\title{
The Comorbidity between Attention-Deficit/Hyperactivity Disorder (ADHD) in Children and Arabic Speech Sound Disorder
}

\author{
Ruaa Osama Hariri \\ English Language Institute, King Abdulaziz University, Saudi Arabia \\ E-mail: ruaa.hariri@gmail.com
}

Doi:10.7575/aiac.alls.v.7n.2p.203

URL: http://dx.doi.org/10.7575/aiac.alls.v.7n.2p.203
Received: 17/12/2015

Accepted: 30/01/2016

\begin{abstract}
Children with Attention-Deficiency/Hyperactive Disorder (ADHD) often have co-existing learning disabilities and developmental weaknesses or delays in some areas including speech (Rief, 2005). Seeing that phonological disorders include articulation errors and other forms of speech disorders, studies pertaining to children with ADHD symptoms who demonstrate signs of phonological disorders in their native Arabic language are lacking. The purpose of this study is to provide a description of Arabic language deficits and to present a theoretical model of potential associations between phonological language deficits and ADHD. Dodd and McCormack's (1995) four subgroups classification of speech disorder and the phonological disorders pertaining to the Arabic language provided by a Saudi Institute for Speech and Hearing are examined within the theoretical framework. Since intervention may improve articulation and focuses a child's attention on the sound structure of words, findings in this study are based on the assumption that children with ADHD may acquire phonology for their Arabic language in the same way, and following the same developmental stages as intelligible children. Both quantitative and qualitative analyses have proven that the ADHD group analyzed in this study had indeed failed to acquire most of their Arabic consonants as they should have.
\end{abstract}

Keywords: speech sound disorder, attention-deficiency/hyperactive, developmental disorder, phonological disorder, language disorder/delay, language impairment

\section{Introduction}

\subsection{Statement of the Problem}

In recent years, there has been an increasing awareness regarding Attention-Deficiency/Hyperactive Disorder (ADHD) amongst Saudi society, as parents of children with ADHD/ADD are now able to access a wider range of health information, generally now more available through the media and the internet. This greater openness has affected the cultural attitude towards early language intervention, which is demonstrated by the rising number of Saudis registering their children for visits with a speech-language pathologist. Moreover, several schools in Jeddah are adopting early intervention programs in order to offer help for children who suffer from behavior problems in addition to and regardless of language delay due to ADHD. Since early intervention may improve articulation and focuses a child's attention on the sound structure of words, this study emphasizes on the fact that many children with ADHD are in need of help in the area of language, which is the first step in their academic education.

Whether children with various ADHD designations are at a greater risk for language difficulties remained unanswered in several studies (Redmond et al., 2011). Recent literature has indicated that the term Speech Sound Disorder should be associated with ADHD, as it recognizes that the disorder may have antecedents in both articulatory and phonological domains (McGrath et al., 2008). The purpose of this study is to investigate the influence of ADHD on speech sounds, through identifying which types of Arabic Speech Sound Disorder (SSD) are particular to children with ADHD in comparison to children of Typical Development. Through identifying both phonetic (articulation) and phonological disorders amongst both groups, this study seeks to discover whether children with ADHD acquire their Arabic consonants and phonology in the same way and following the same developmental stages as intelligible children. This sheds light upon Arabic SSD associated with ADHD as a first attempt in identifying speech symptoms for this disorder amongst the literature.

\subsection{Importance of the Problem}

Recent literature has indicated that children with articulation and phonological disorders who are not identified and treated early may encounter academic, social and psychological difficulties. Since ADHD is claimed to be one of the most misunderstood, (Bender, 1997, cited in Lee, 2004) and one of the most controversial child medical diagnoses (Wolraich, 1999) it is momentously critical that Speech Sound Disorder caused by ADHD is identified. This study is an attempt to identify both articulation and phonological disorders amongst Arabic speaking children with ADHD. 


\subsection{Literature Review}

A central theme of this literature review is the association between ADHD and Speech Sound Disorder (SSD). Speech Sound Disorder is an expressive language disorder that is said to be a characteristic of ADHD. AttentionDeficit/Hyperactivity Disorder (ADHD), is defined it as a neurobiological behavioral disorder characterized by chronic and developmentally inappropriate degrees of inattention, impulsivity, and in some cases hyperactivity (CHADD, 2001, cited in Rief, 2005). Under the umbrella term (ADHD), there are three types of disorders included: the predominantly inattentive type (ADD), the predominantly hyperactive/impulsive type (ADHD), and the combined type (ADHD/ADD). The final type has a significant amount of symptoms in all three core areas (inattention, impulsivity and hyperactivity) and it is the most common type of ADHD, describes Rief (2005).

Thomas Brown (2005) explains that the core problem in ADHD is not a lack of willpower, but chronic and often lifelong impairment of the executive functions of the brain. The concept of 'executive functions' refers to facets of the cognitive management functions of the brain, which most researchers agree that this term should be used to refer to brain circuits that prioritize, integrate, and regulate other cognitive functions. In terms of language, children with ADHD often have combined problems in listening, speaking, and pragmatics, and each of these communicative activities involves executive functions (Brown, 2005). According to the American Academy of Pediatrics (2000) ADHD is considered the most common neurobehavioral disorder of childhood, and among the most prevalent chronic mental health conditions affecting 4-7 \% of school aged children, approximately three times more boys than girls (Rief, 2005, p.4). Fewell \& Deutscher (2002) affirm that the number of children diagnosed with attention deficit hyperactivity disorder (ADHD) is rising, and is now considered the most common neuropsychiatric syndrome in US school-age children, affecting approximately two million children.

Currie \& Stabile (2006) note that ADHD is diagnosed in more than half of all child mental health referrals. However, the main diagnostic criteria for this disorder are laid out in the Diagnostic and Statistical Manual of Mental Disorders according to the American Psychiatric Association (1994). It states that to be diagnosed with ADHD, a child must have six or more symptoms; have had symptoms by age 7; and be suffering impairment from the symptoms in two or more settings (usually home and school). Overall, diagnosis of ADHD is based solely on the observation of behaviors, conclude Currie \& Stabile (2006). Rief, (2005) notes that it has been witnessed that children with ADHD often have co-existing learning disabilities and developmental weaknesses or delays in some areas, including speech/language, motor skills, reading skills, remembering numbers, and letter/sound association.

The difficulties that children with ADHD face are amongst the list of possible warning signs of learning disabilities. The list has been outlined by the International Dyslexia Association (2003, cited in Rief, 2005) which include pronunciation problems, difficulty learning new words and following simple directions, difficulty rhyming words, difficulty in understanding questions, expressing wants and desires, and a lack of interest in storytelling. In terms of cognition, learning difficulties include for example, trouble memorizing the alphabet or days of the week. In terms of attention, children display high distractibility, impulsive behavior, hyperactivity, difficulty staying on task/changing activities, and constant repetition of an idea. According to Rief, (2005) many of these behaviors are also indicators of $\mathrm{ADHD}$, as well as learning disabilities and some developmental disorders.

According to the American Speech-Language-Hearing Association (1997), a greater percentage of children with ADHD are somewhat delayed in the onset of talking 6\% - 35\% than children without ADHD 2\% - 5.5\% (Hartough \& Lambert, 1985; Szatmari, Offord, \& Boyle, 1989). Also, students with ADHD are more likely than children without ADHD to have a diagnosis of language disorders (Cantwell, Baker, \& Mattison, 1979, 1981; Love \& Thompson, 1988; Trautman, Giddan, \& Jurs, 1990, cited in ASHA, 1997). Furthermore, many professionals have inferred that children with ADHD also experience auditory perceptual difficulties (Keller, 1992; Willeford \& Burleigh, 1985; Burd \& Fisher, 1986, cited in ASHA, 1997).

Several studies conducted in the 1980's led to agreement consensus that speech-language impairment co-occurred with ADHD (Baker and Cantwell, 1992 cited in McGrath et al. (2008). However, advances in the definition of speechlanguage disorders have encourage renewed interest in the overlap of speech-language disorders and ADHD (Snowling et al. 2006, cited in McGrath et al., 2008).

Camarata \& Gibson (1999) note that since the actual nature of Expressive Language Disorder in children with ADHD in terms of semantic, morphological, syntactic, or pragmatic disorders has not been directly specified, they have presented a direct analysis of the potential interaction between ADHD subtypes and pragmatic language deficits. Their study argues that ELD and Mixed Receptive-Expressive Disorders are potentially related to pragmatic deficits in children with ADHD, which are defined as difficulties in the conversational aspects of language (Miller, 1981, cited in Camarata \& Gibson, 1999). They also assert that 'intelligibility' within the pragmatic domain cannot be distinguished from the phonology domain. For example, if a child has phonological errors, such as sound substitution, and they are sufficient errors in his/her sound system that conversational exchange becomes hindered, then the phonological disorders have a negative impact on the pragmatic domain as well.

Furthermore, Cohen et al. (2000) noticed in a number of study samples that a range of psychiatric disorders was represented amongst children with Language Impairment (LI), and the most frequent psychiatric diagnosis among children with LI was ADHD. In their study, the language, achievement, and cognitive processing characteristics of 166 psychiatrically referred 7-14 year-old children were examined in four groups: ADHD with and without LI, and other psychiatric diagnoses with and without LI. However, results indicated that children with LI were at the most 
disadvantage, regardless of the nature of the psychiatric diagnosis. It suggested that children with ADHD have problems with working memory, as indicated by their below-average scores on their task, but they did not perform as poorly as children with LI.

Also, in a study conducted by Redmond, Thompson, and Goldstein (2011), it was discovered that there is in fact a clear phenotypic boundary between Specific Language Impairment (SLI) and ADHD. This was based on the results of their study, which differentiates between SLI, ADHD, and Typical Development amongst 7-8 year old children. The term Specific Language Impairment is defined as difficulties in acquiring language in the absence of any other mental, sensory, motoric, emotional, or experiential deficits (Gillam et al., 2011). In their study, Redmond et al. (2011) measured tense marking, non-word repetition (percentage of phonemes correctly produced), sentence recall, and narrative measures accurately in each case. Variability in tense-marking performance was evident only in the SLI group, and children with ADHD performed better than children with SLI on sentence recall measures. Although their study did not find any evidence that children with ADHD (combined type) had particular difficulties in this study, it remained an open question whether children with various ADHD designations (predominately inattentive; predominately hyperactive-impulsive) are at greater risk for language difficulties.

However, the McGrath et al. (2008) study focused on the comorbidity between ADHD symptoms and Speech Sound Disorder (SSD). Speech Sound Disorder is a developmental disorder characterized by speech production errors that significantly impact intelligibility (Shriberg, 2003, cited in McGrath et al., 2008, p. 151). For example, children with SSD may make age-inappropriate speech sound deletions (e.g., "do" for "dog") and/or substitutions (e.g., "ti" for "see"). According to the American Psychiatric Association (2000), this disorder is referred to as a Phonological Disorder. Although the terms Phonological Disorder and SSD refer to the same constellation of clinical signs, the latter is currently preferred because it recognizes that the disorder may have antecedents in both articulatory (sensory motor) and phonological (cognitive-linguistic) domains. The term SSD has recently been adopted as the classification entity for this disorder by American Speech-Language Hearing Association (ASHA).

Cases of ADHD patients in Saudi Arabia were investigated in a study conducted by Al-Haidar (2003) at the child psychiatric clinic at King Khalid University Hospital in Riyadh. Out of 416 case records, 106 (25.5\%) patients were diagnosed with ADHD. The majority (93.4\%) were Saudi nationals below the age of 19 who had been attending the child psychiatric clinic for ten years. The most common associated disorder was expressive language disorder, which constituted an average of $(28.3 \%)$.

Haidar (2003) noted that ADHD is quite strongly associated with a range of abnormalities in psychological and motor development according to Taylor, (1986), and the most typical abnormalities found are immature articulation and language delay (Reeves 1987). Because of the comorbidity between ADHD and Speech Sound Disorder, speechlanguage pathologists (SLP) and audiologists must be aware of current perspectives on ADHD in order to function effectively in working with patients with ADHD. According to ASHA (1997), speech-language pathologists and audiologists are increasingly involved with students with ADHD. They are often among the first to evaluate children and youth suspected of having ADHD because of the co-occurrence of ADHD with language learning disabilities and central auditory processing disorders.

\subsection{Hypotheses and Research Design}

The aim of this study is to investigate the influence of ADHD on speech sounds, through identifying which types of Arabic SSD are particular to children with ADHD in comparison to children of Typical Development. Through identifying both phonetic (articulation) and phonological disorders amongst both groups, this study seeks to discover if children with ADHD acquire their Arabic consonants and phonology in the same way and following the same developmental stages as intelligible children. Accordingly, this study will serve to shed light upon Arabic Speech Sound Disorders as a development in identifying the speech symptoms caused by ADHD. The research questions are, therefore, as follows:

1. Do children with ADHD acquire their Arabic consonants in the same way and following the same developmental stages as children of TD?

2. How are the articulation errors and phonological processes amongst the ADHD group and TD group both similar and different?

3. Which of the three subtypes of ADHD are related to Arabic Speech Sound Disorder?

\subsection{Significance and Originality}

Most of the studies tackling the correlation between ADHD and language disorders were conducted in relation to the English language and none have been conducted in relation to the Arabic language. This study is an attempt to fill this gap through identifying Arabic Speech Sound Disorder amongst children with ADHD symptoms, and thus represents the first examination of the performances of children with ADHD on the Arabic articulation and phonological markers of disrupted language development. Therefore, the significance of this study lies in the scarcity of studies that have dealt with this language-behavior relationship between Arabic Speech Sound Disorder and ADHD.

The importance of identifying the normal progression of Arabic phonemic acquisition and distinguishing it from disordered/delayed phonological development is highlighted for the first time in Amayreh's (2003) study. The

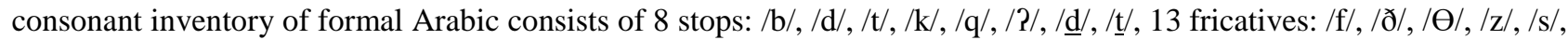

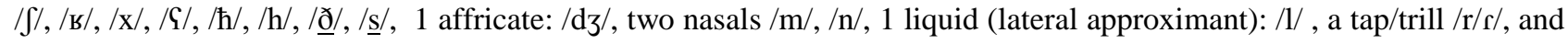


two glides /w/, /j/. Attention should be drawn to the emphatic consonant phonemes which except for /q/are written with an underline: $/ \underline{\mathrm{d}} /, / \mathrm{t} /, / \underline{\mathrm{s}} /$, and $/ \underline{\mathrm{d}} /$ as each has a non-emphatic cognate. Three other consonants $/ \mathrm{r} /, / \mathrm{x} /$, and $/ \mathrm{s} /$ may be emphatic in certain phonetic environments. The age at which children acquire their consonants in many languages is usually earlier than Arabic, which Amayreh (2003) confirms is usually completed at a later age $(8 ; 4)$. In comparison between English, German, and Arabic, the last consonant acquisition is usually earlier in the former languages than in

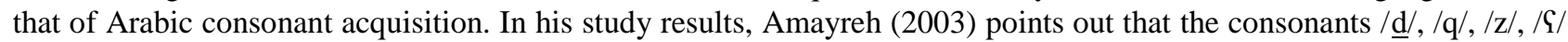

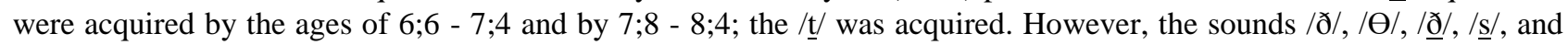
$/ \mathrm{d} 3 /$ were not even acquired by the eldest children $(8 ; 4)$ although they were produced using some acceptable forms.

\section{Method}

According to Davis \& Bedore (2008, cited in Gillam et al., 2011), describing an articulation and phonological development as disordered or delayed is based on a comparison of the child's speech to the articulation and phonological patterns of children of a comparable age who are developing normally. Thus, the data for children with ADHD is compared to that of children without ADHD for the purpose of identifying articulation and phonological developmental conditions for each subject. The data was analyzed following two procedures:

1) Identifying speech sound disorder according to Amayreh's (2003) classification of Arabic consonant acquisition

2) Identifying Arabic phonological disorders

To identify the normal progression of phoneme learning and distinguish it from disordered, a rationale is provided through the use of Amayreh's (2003) classification of Arabic consonant acquisition for normal developing children. A checklist of common phonological disorders pertaining to the Arabic language, provided by a Saudi institute for speech and hearing therapy is examined within the methodology.

Both qualitative and quantitative analyses are examined within the theoretical framework which includes both phonetic and phonological science. The subjects were a total of 20 children of different Arabic nationalities and within the age category of 5-7 years that had been residing in Jeddah in Saudi Arabia. The ADHD group included 10 children that were enrolled for speech-language therapy at the Institute. A control group consisting of 10 children with Typical Development (TD) was used to compare both similar and distinctive articulation and phonological disorders with the ADHD group.

Profiles were collected for children with Attention-Deficit/Hyperactivity Disorder (ADHD) enrolled at the institute for speech-language therapy. The ADHD sample group included 10 children aged $(5-7)$ years, with 8 boys and 2 girls, from different Arab nationalities (5 Egyptians, 1 Jordanian, 3 Saudis, and 1 Yemeni). All had been consecutively referred to an institute for speech and hearing for articulation assessment and speech therapy. Of the 10 children with ADHD, five of them had the combined type (ADHD/ADD), two had the predominantly hyperactive/impulsive type (ADHD), and three had the predominantly inattentive type (ADD).

The ADHD patients chosen for this study did not exhibit aggressive behavior, although several had behavioral issues (such as hyperactivity) which made it difficult for the researcher to test them as they had trouble sitting patiently and following orders with someone other than the speech-language pathologist (SLP). Therefore, due to difficulties in handling these children at the institute for speech assessment, and in order to ease the data gathering process, it was decided that the SLP would be the ones to test the children at the institute, using the their specific articulation test. The researcher was then able to obtain the data via DVD recorded sessions for each child. The articulation test results were also marked out for pronunciation errors by the pathologist, and delivered to the researcher for further revision and analysis.

\subsection{Measures}

The children with ADHD in this study had received recommendations for facilitation of receptive and expressive language skills using a family based language stimulation program provided by a Saudi institute for speech and hearing. They had also been assessed through several examinations prior to this study and the information in each patient record file was reviewed for the purpose of categorizing the ADHD patients under the same group of similar characteristics. Therefore, the information that was obtained from each patient file included all of the following: Summary of the child's medical history obtained by questioning the parents, Oral Speech Mechanism Screening Examination (OSMSER), Articulation Test, Language Evaluation Protocol (Expressive/Receptive language), Behavior Protocol Checklist \& Recommendations (Attention) (Hyperactivity) (Impulsivity), and Hearing Screening.

The entire ADHD group of participants for this study had ADHD symptoms in addition to an articulation/phonological disorder. They had all demonstrated normal hearing acuity during an audiometric (hearing) screening and achieved a nonverbal IQ standard score of over 70. All of the ADHD patients had results in their language evaluation protocol as moderate receptive language delay and severe expressive language delay. It should be noted that 8 out of the 10 ADHD patients in this study had been taking prescribed behavioral medication prior to and during the period of their assessment and treatment at the Institute. Children with mild or severe mental retardation, hearing impairment, or who had autistic features had been excluded from the study. It must be noted that the portion from which the subjects in the ADHD group were selected for this study had articulation/phonological disorders, in addition to language delay/disorder. In order to avoid the effect of behavioral developmental disorders other than ADHD/ADD, patients with autistic features (PDD) were excluded from this study. 


\section{TD Subjects}

The Typical Development (TD) group included a total of 10 children ages ( $5-7)$ years old, including 7 boys and 3 girls from a Saudi Preschool. The subjects were also from various Arab nationalities (2 Egyptians, 2 Sudanese, 5 Saudis, and 1 Syrian). They were all identified by the school's teachers as children with intelligible speech (regardless of their behavior issues) which had required them to be placed in this particular school for behavioral modification only. Each child that was included in the TD group had an academic profile which revealed Typical Development without previous speech-language therapy intervention. Therefore, the TD group was a suitable control group for the comparison needed with children of ADHD.

\section{The Articulation Test}

Although the participants spoke different colloquial forms of Arabic, the Arabic formal version of the language used in the articulation test was Educated Spoken Arabic (ESA), which is the form that is taught in schools. The data was extracted from previous DVD recordings from speech sessions for children with ADHD during their assessment by a speech-language pathologist. The remainder of the data for the TD group was extracted from voice recordings of 10 participants during their individual assessment sessions with the researcher while using the same articulation test, which uses 38 pictures in a book to elicit 50 words for all 28 Arabic consonants occurring in all three positions (initial, medial, and final). Most of the consonants were used in at least all three positions, while others occurred more frequently amongst all 50 words. For the purpose of identifying Arabic phonemes, the researcher utilizes the Arabic phonemic inventory according to IPA guidelines which has been adopted by the American Speech-Language Hearing Association. The data for the phonological processes was written inside tables, which includes examples of the children speech sound errors that are a transcription and translation of the words used in the articulation test.

\subsection{Method of Analysis}

Both Phonetic and Phonological science as a framework approach in the assessment of the ADHD group and TD group, through identifying which types of Arabic SSD are most common amongst all subjects. The study of linguistic tools uses Phonetics for identifying articulation disorders and Phonology for identifying phonemic disorders. These tools are portrayed as a mechanism of interactional dominance by the speech pathologist profession, which have also been utilized in the data collection and analysis. The analysis tables include transcriptions and translations of some of the Arabic speech sound errors during the children's assessment test.

The first procedure was in identifying children's Arabic Articulation Disorders according to Amayreh's (2003) study, which indicates that the acquisition of Arabic consonants is divided into 3 stages: early - intermediate - late. The

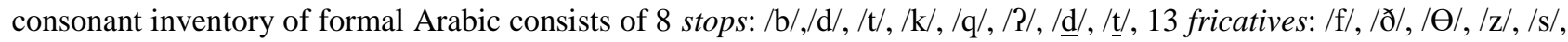

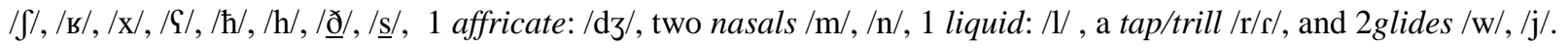

According to Amayreh and Dyson (1998), the consonants which fall under the early stage of acquisition (2-3;10 years) were in the following order: $/ \mathrm{n} /, / \mathrm{w} /, / \mathrm{m} /, / \mathrm{t} /, / \mathrm{k} /, / \mathrm{f} /, / \mathrm{h} /, / \mathrm{b} /, / \mathrm{d} /$, and $/ 1 /$. Those that go under the intermediate age group (4-6;4 years) were in the following order: $/ \mathrm{x} /, / \mathrm{s} /, / \mathrm{J} / / \mathrm{h} /, / \mathrm{r} / / \mathrm{s} /$, and $/ \mathrm{j} /$. Finally, those classified as late consonants $(6 ; 6-$ $8 ; 4$ years) were in the following order: /t $/, / \underline{\mathrm{d}} /, / \mathrm{q} /, / \mathrm{R} /, / \mathrm{d} /, / \Theta /, / \underline{\mathrm{d}} /, / \mathrm{z} /, / \underline{\mathrm{s}} /, / \mathrm{A} /$, and /dz/ (Amayreh, 2003). Therefore, consonant acquisition amongst both groups in this study was based on a comparison with the acquisition of Arabic consonants as identified by Amayreh (2003).

The second step in the analysis was to identify children's Arabic Phonological Disorders according to the checklist of Arabic Phonological Processes/Disorders prepared by the institute. The phonological disorders included in the checklist specified four major processes:

- Omissions (deletions): Certain sounds are not produced or entire syllables may be deleted. e.g., /djk/ is pronounced as /di/ (rooster).

- Substitutions (replacement): One or more sounds are substituted for another. e.g. / $\underline{ð i f i r / ~ i s ~ p r o n o u n c e d ~ a s ~ / ~} \underline{\text { difill/ }}$ 'nail'.

- Additions (or insertions): an extra sound or sounds are added to the intended word. e.g. / $/ \mathrm{u} \mathrm{f} / \mathrm{pronounced}$ as $/ \mathrm{Su} \mathrm{jb} /$ 'nest'

- Distortions: Sounds are changed slightly so that the intended sound may be recognized but would sound

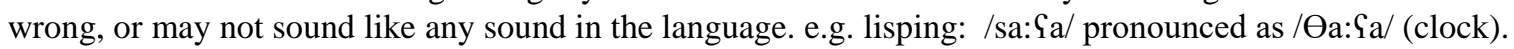

Under these four major types of phonological processes, the JISH checklist of common Arabic phonological processes was used for the purpose of identifying which Arabic phonological disorders are specific to children with and without ADHD. Therefore, the Arabic Phonological Processes/Disorders identified by JISH include some of the following processes: Devoicing; Deletion (initial-medial-final); Assimilation; Replacement; Metathesis; Glottal Replacement/Addition; De-emphasization; Epenthesis; Apicalization; Migration; De-nasalization; Stopping of Fricatives; Fronting; Backing of Stops or Fricatives; Fricatives Replacing Stops; Stops Replacing Fricatives; and Sound Preference Substitution.

\section{Results}

In order to answer the research questions data was analyzed after it had been collected through the JISH Articulation Test that both groups of children had undertaken. The test had elicited fifty Arabic words from all twenty children. The test for each group had been analyzed separately, and then compared and contrasted. It was important to identify the 
phonemic acquisition of the Arabic consonants amongst the Typical Development group in order to distinguish it from the disordered phonological development produced by children with ADHD.

\subsection{Articulation Disorders for the Typical Development Group}

The first group to be analyzed was the Typical Development group (TD), which included 10 children. Their speech was considered intelligible with minor errors due to their incomplete acquisition of all the Arabic consonants. For the purpose of identifying articulation and phonological developmental conditions for each participant, the data was analyzed by using the scientific mechanism of Phonetics for all 28 Arabic consonants. Figure 1 bellow summarizes information for the percentages of the easiest and most difficult Arabic consonants, ranging from the easiest beginning on the left side. Note: due to the Excel sheet limitations, the emphatic symbols which were underlined have been replaced with different symbol in each figure; e.g. $/ \underline{\mathrm{s}} / \rightarrow / \mathrm{s} /$.

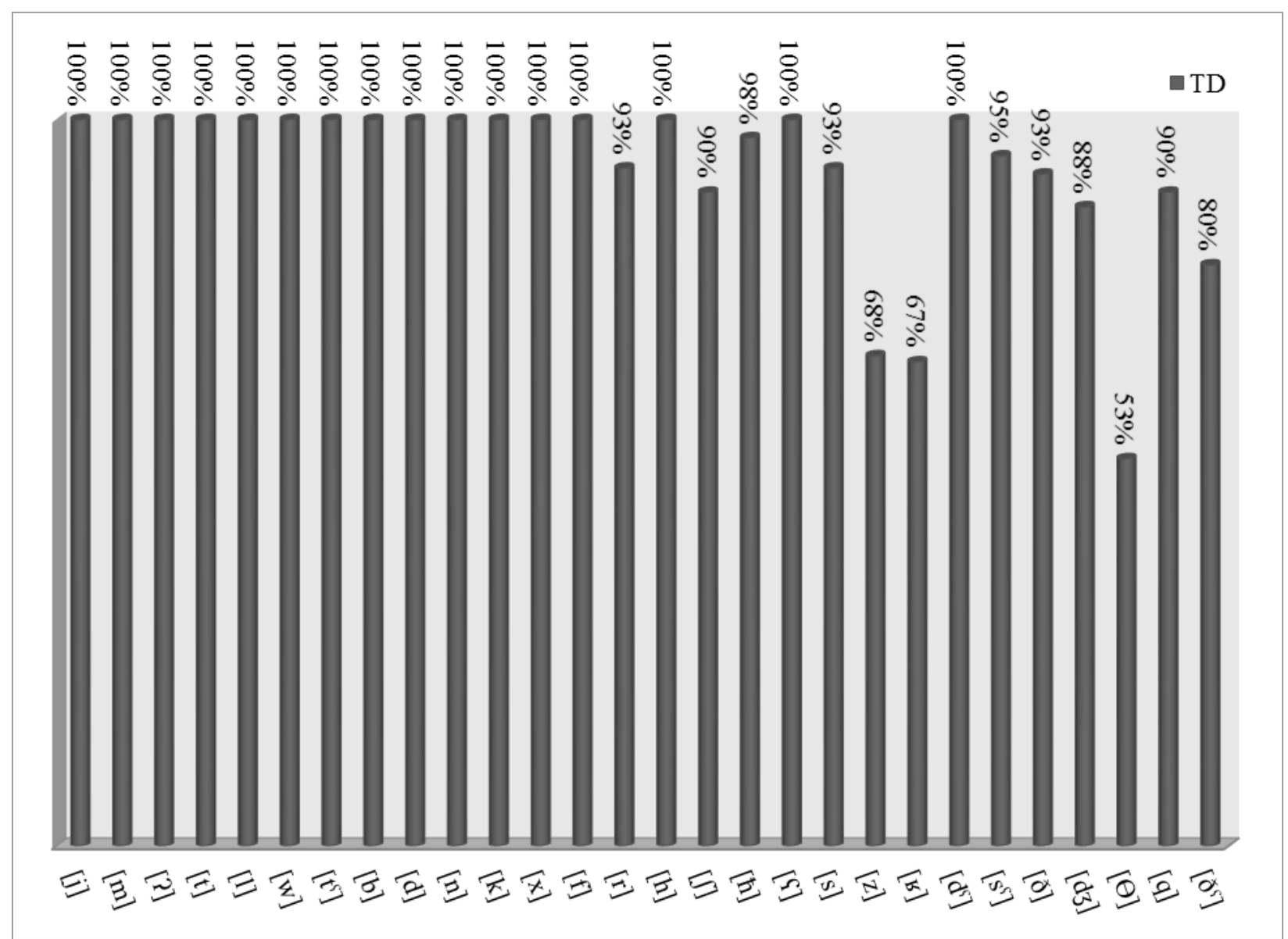

Figure 1. Range of acquired Arabic consonants amongst TD group

Starting with the left side are the $100 \%$ correctly pronounced consonants which are the following: /t/ , /f/ , /h/ , /n/ , /m/ , $/ \mathrm{b} /, / \mathrm{d} /, / \mathrm{d} /, / \mathrm{t} /, / \mathrm{x} /, / \mathrm{l} /, / \mathrm{w} /, / \mathrm{j} /, / \mathrm{k} /, / \mathrm{S} /$ and $/ \mathrm{R} /$. The Arabic sounds which had been replaced by other sounds were the following: /dz/, /z/, /q/, / $\underline{\jmath} /, / \Theta /, / \mathrm{z} /, / \underline{\mathrm{s}} /, / \mathrm{s} /, / \mathrm{J} /, / \mathrm{r} / / \mathrm{s} /$, and $/ \mathrm{h} /$. Several consonants occurred more frequently than others on the test and therefore resulted in varied total numbers amongst the consonants.

It was noticed from the analysis that the sounds which had been altered and replaced with near sounds, de-emphasized, or deleted were considered quite normal for the TD groups which was (5-7) years. According to Amayreh's (2003) classification for the acquisition of the Arabic consonants, these sounds fall under the intermediate and late consonants. Although some of the intermediate and late consonants had been already acquired by all children such as $/ \underline{\mathrm{t}} /, / \mathrm{S} /, / \mathrm{x} /, / \mathrm{j} /$, $/ \mathrm{h} /$ and $/ \underline{\mathrm{d}} /, 12$ other sounds were amongst the errors which these children had problems pronouncing, such as /dz/, /z/, /q/, / $\underline{\mathrm{d}} /, / \Theta /, / \mathrm{z} /$, /s $/, / \mathrm{s} /, / \mathrm{J} / / \mathrm{r} / / \mathrm{s} /$, and $/ \mathrm{h} /$.

The only sound that was considered deviant from Amayreh's age division was the pharyngeal fricative $/ \hbar /$, which is considered amongst the early sounds which should have been acquired by age 3; 6 . Those that are included in the intermediate stage (4- 6;4) in Amayreh's study were in the following order: / $\mathrm{x} /, / \mathrm{s} /, / \mathrm{s} /, / \mathrm{h} /, / \mathrm{r} / / \mathrm{s} /$, and $/ \mathrm{j} /$. Therefore, this group had acquired most of their Arabic consonants quite well, correctly pronouncing 16 consonants $100 \%$ accurately with sound changes occurring in 12 sounds. Figure 2 bellow demonstrates the highest percentage of sound errors amongst the TD group. 


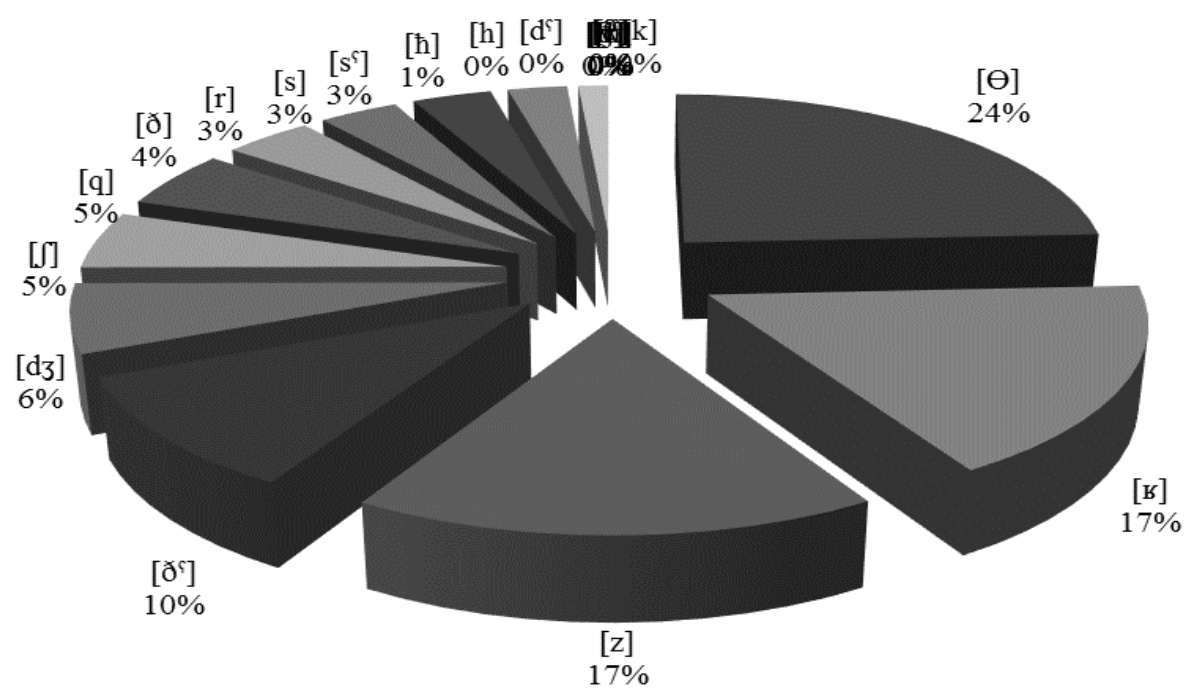

Figure 2. Most common sound errors amongst TD group

\subsection{Articulation Disorders for the ADHD Group}

The second group to be analyzed was that of children with ADHD, which was comprised of 10 children. Their speech was considered highly unintelligible with major sound errors. This group had trouble pronouncing almost all of the Arabic consonants. Figure 3 summarizes the information for the percentages of the easiest and most difficult Arabic consonants, ranging between the easiest from the left side to the most difficult which reaches all the way to the end of the right side of the chart.

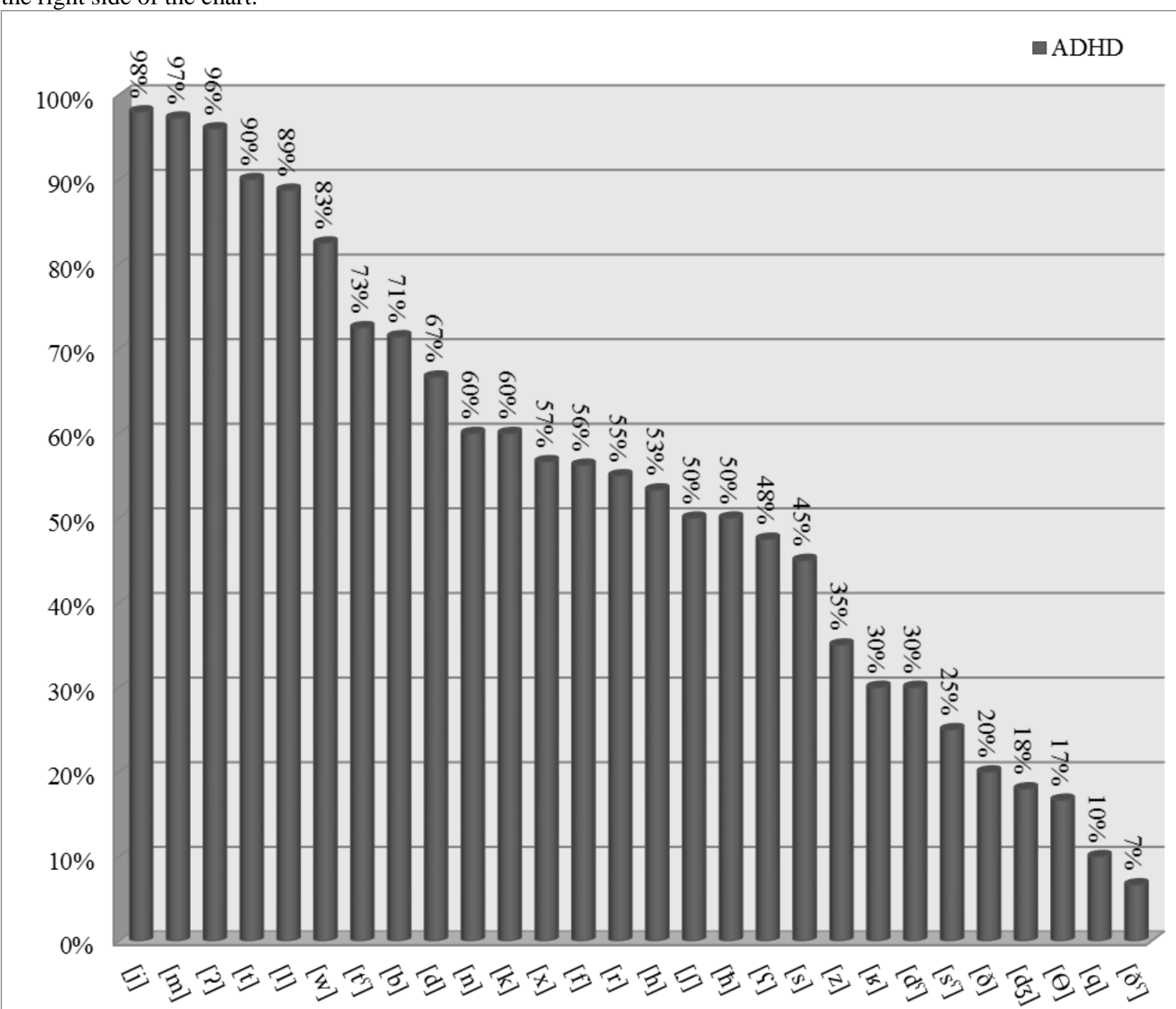


Starting with the left side are the mostly frequently correctly pronounced consonants, of which $98 \%-83 \%$ ) were the following six, in order from easiest: $/ \mathrm{j} /, / \mathrm{m} /, / \mathrm{R} /, / \mathrm{t} /, / \mathrm{l} /$, and $/ \mathrm{w} /$. However, the most difficult sounds $(25 \%-7 \%)$ were the

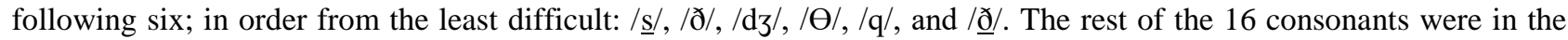
middle range, as they were considered to be quite difficult $(73 \%-30 \%)$ in the following order: /t/, /b/, /d/, /n/, /k/, /x/,

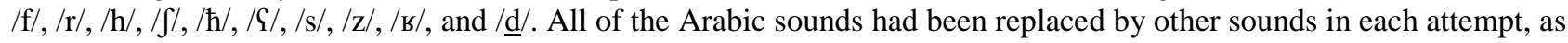
shown in the pie chart below (Figure 4).

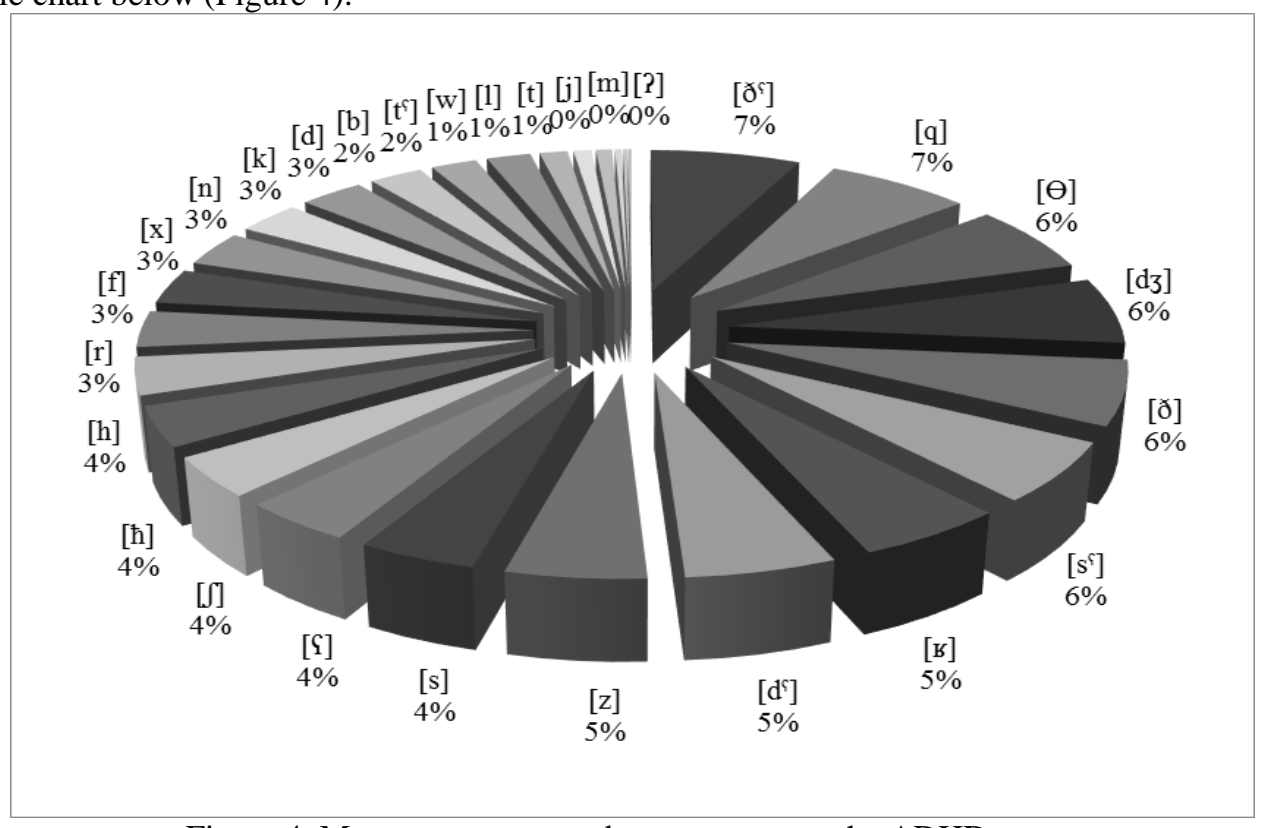

Figure 4. Most common sound errors amongst the ADHD group

It was noticed from the analysis that the sounds which had been altered and replaced with near sounds, de-emphasized, or deleted were considered irregular for the groups which were within the age (5 - 7) years. According to Amayreh's (2003) classification for the acquisition of the Arabic consonants, the only sound which deviates from his classification was the glottal stop / / which was placed as a late consonant. It was noticed that the glottal stop / / was frequently pronounced and used as a replacement for most of the difficult sounds, regardless of several deleted occurrences and one replacement. The sounds that were produced with less effort were amongst the supposed early/intermediate stage in Amayreh's study, and were the following:

$/ \mathrm{j} /, / \mathrm{m} /, / \mathrm{R} /, / \mathrm{t} / \mathrm{l} / \mathrm{l} / \mathrm{l} / \mathrm{w} /$. The ADHD group did not have difficulty pronouncing these sounds as the other sounds. The following chart demonstrates the results of both groups (ADHD and TD) in an effort to distinguish the differences in pronouncing of all 28 Arabic consonants:

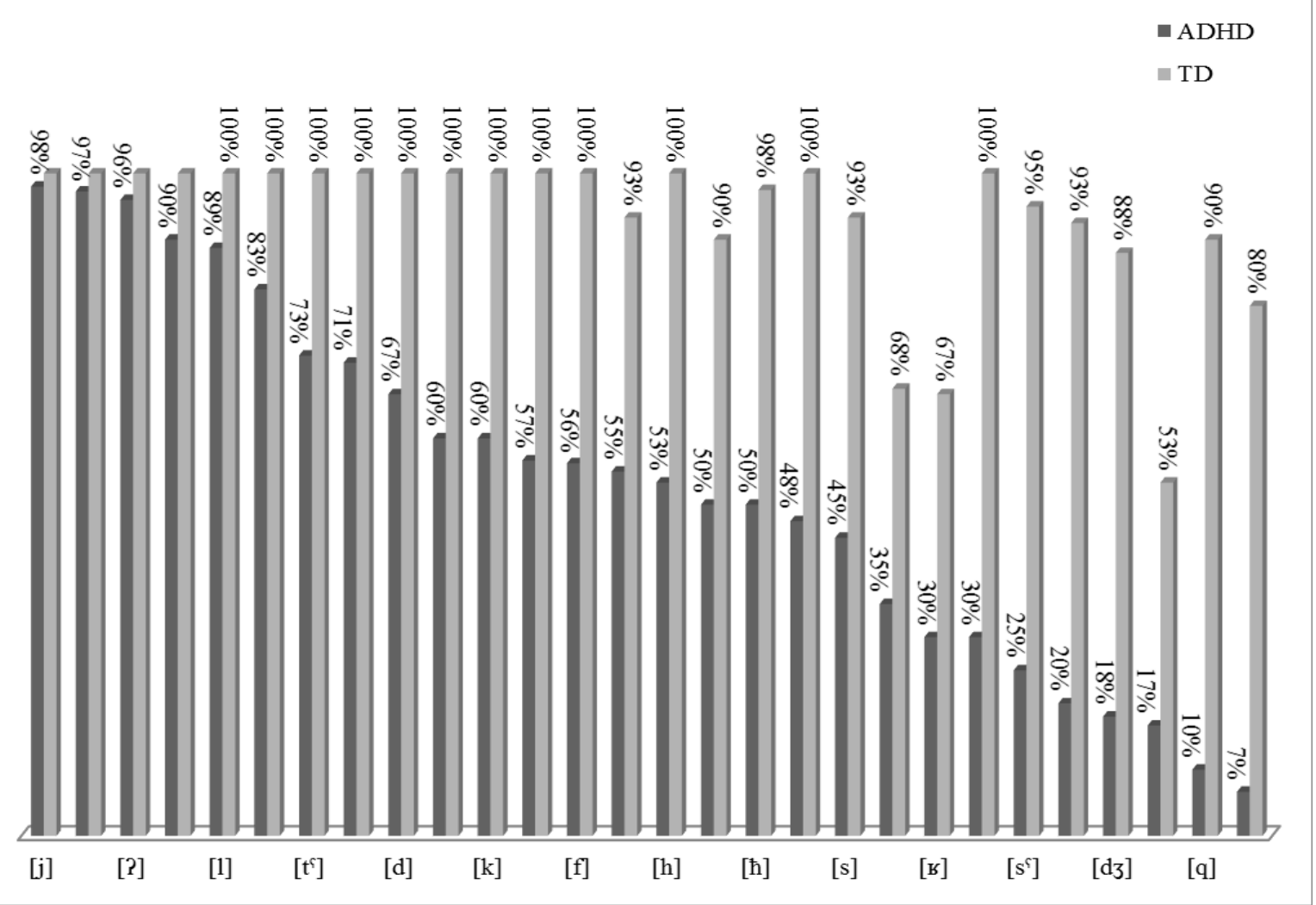

Figure 5. Range of simplest and most difficult consonants amongst both Groups 
Based on Amayreh's study (2003), the ADHD group had indeed not acquired most of their Arabic consonants as they should have. Also, in comparison with the TD group, stark differences stand out. The total number of correctly pronounced consonants amongst the TD group was 1443, and 895 for the ADHD group. The total number of changed consonants amongst the TD group was 57, and 244 for the ADHD group. However, 327 from a total of 1510 sound attempts were not pronounced at all amongst the ADHD group while the TD group did not demonstrate any nonpronounced sounds. The non-pronounced sounds were particular to the ADHD group, and were mostly of the

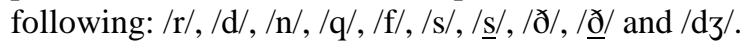

\subsection{Analysis and findings for the Phonological Disorders of Arabic consonants}

After having analyzed the articulation disorders amongst both groups, we now turn to the second step in our analysis method, which is identifying the phonological processes and most common types of phonemic errors according to the JISH checklist of Arabic phonological processes/disorders. This section will provide tables to describe each type of phonological processes with examples.

\subsection{Phonological Disorders for the Typical Development Group}

The total number of types of phonological disorders amongst the Typical Development group was 11, which is considered appropriate due the difficultly of the Arabic fricatives. As Amayreh (2003) mentions, this is common in dialects, as there is a tendency for dialects to move towards less marked forms. Therefore, most of the late consonants: $/ \underline{\mathrm{t}} /, / \underline{\mathrm{d}} /, / \mathrm{q} /, / \mathrm{l} /, / \mathrm{d} /, / \Theta /, / \underline{\mathrm{d}} /, / \mathrm{z} /, / \underline{\mathrm{s}} /, / \mathrm{I} /$, and $/ \mathrm{d} \mathrm{z} /$, are more marked than their common replacements so that a 'voiced' is replaced with a 'voiceless', as in example (1) in the table; a fricative is replaced with a stop as in the example in (4), and an affricate is replaced with a fricative, as in the examples in (3). Emphatic sounds are replaced with non-emphatic sounds (a consonant of no secondary articulation) as in the examples in (2). Therefore, these phonological errors are due to the fact that this age group has not yet acquired all of their Arabic consonants, which are beyond their age level. The following table demonstrates types of phonological processes amongst the TD group with examples:

Table 1. Phonological Processes for TD group

\begin{tabular}{|c|c|c|c|}
\hline $\begin{array}{c}\text { Eg. } \\
\text { Number }\end{array}$ & Type of Phonological Disorder & Examples & Translation \\
\hline 1 & $\begin{array}{l}\text { Devoicing: voiced sound is replaced } \\
\text { with voiceless; } \\
/ \mathrm{d} / \rightarrow[\mathrm{t}], / \mathrm{B} / \rightarrow[\mathrm{x}]\end{array}$ & $\begin{array}{l}\text { e.g.1: /durdz/ pronounced as /turz/ } \\
\text { e.g.2: /sams/ pronounced as /samx/ }\end{array}$ & $\begin{array}{l}\text { Drawer } \\
\text { Glue }\end{array}$ \\
\hline 2 & $\begin{array}{l}\text { De-emphasization: emphatic sounds } \\
\text { become non-emphatic; } \\
/ \underline{\text { d} / \rightarrow[\mathrm{d}], / \underline{\mathrm{s}} / \rightarrow[\mathrm{s}]}\end{array}$ & $\begin{array}{l}\text { e.g.1: /ðifir/ pronounced as /difir/ } \\
\text { e.g.2:/Pasfar/ pronounced as /Pasfar/ }\end{array}$ & $\begin{array}{l}\text { Finger nail } \\
\text { Yellow }\end{array}$ \\
\hline 3 & $\begin{array}{l}\text { De-affrication: An affricate is } \\
\text { replaced with an fricative; } \\
/ \mathrm{d} z / \rightarrow[\mathrm{z}, \mathrm{\partial}]\end{array}$ & $\begin{array}{l}\text { e.g.1:/durdz/ pronounced as /durz/ } \\
\text { e.g.2:/dzaras/pronounced as /ðaraӨ/ }\end{array}$ & $\begin{array}{c}\text { Drawer } \\
\text { Bell }\end{array}$ \\
\hline 4 & $\begin{array}{l}\text { Stopping of fricatives: stop replaces } \\
\text { fricative } / \mathrm{d} / \rightarrow[\mathrm{z}]\end{array}$ & e.g. /zuhu:r/ pronounced as /duhu:r/ & Flowers \\
\hline 5 & $\begin{array}{l}\text { Deletion: Final consonant deletion; } \\
/ \mathrm{s} / \rightarrow[\varnothing] \\
\text { Middle consonant deletion; } \\
/ \mathrm{r} / \rightarrow[\varnothing]\end{array}$ & $\begin{array}{l}\text { e.g.1: /sams/ pronounced as / } / \text { sam/ } \\
\text { e.g.2:/Parnab/pronounced as / } \mathrm{Panab} /\end{array}$ & $\begin{array}{l}\text { Glue } \\
\text { Rabbit }\end{array}$ \\
\hline 6 & $\begin{array}{l}\text { Insertion: adding a stop at word } \\
\text { ending; } \varnothing \rightarrow[\mathrm{b}]\end{array}$ & e.g. $/ \mathrm{Gu} / /$ pronounced as $/ \varsigma \mathrm{u} \mathrm{Jb} /$ & Nest \\
\hline 7 & $\begin{array}{l}\text { Backing of fricatives: alveolar } \\
\text { fricative replaces dental fricative; /s/ } \\
\rightarrow[\Theta]\end{array}$ & e.g. /muӨallaӨ/ pronounced as /musallas/ & Triangle \\
\hline 8 & $\begin{array}{l}\text { Fronting of fricatives: Dental } \\
\text { fricative replaces alveolar fricative; } \\
/ ð / \rightarrow[\mathrm{z}]\end{array}$ & e.g. /Pazraq/ pronounced as / Paðraq/ & Blue \\
\hline 9 & $\begin{array}{l}\text { Sound Preference Substitution: } \\
\text { lateral is used to replace trill; } \\
/ \mathrm{r} / \rightarrow[1]\end{array}$ & e.g. /zuhu:r/ pronounced as / /zuhu:1/ & Flower \\
\hline 10 & $\begin{array}{l}\text { De-emphasization: Velar stop } \\
\text { replaces uvular emphatic stop; /k/ } \\
\rightarrow[\mathrm{q}]\end{array}$ & e.g. /baqara/ pronounced as /bakara/ & Cow \\
\hline 11 & $\begin{array}{l}\text { Stopping of fricatives: Alveolar stop } \\
\text { replaces dental fricative; } / ð / \rightarrow[\mathrm{d}]\end{array}$ & /ðura/ pronounced as/dura/ & Corn \\
\hline
\end{tabular}

Figure 6 bellow demonstrates information regarding the types and number of phonological processes amongst all 10 children of Typical Development. The most common types of phonological disorders, in order from greatest number of occurrences to the least amount, were: Fronting of fricatives and De-emphasization (10) - stopping of fricatives (9) devoicing and deletion (7) - de-affrication (5) - sound preference substitution (3) - and insertion (2). 
109

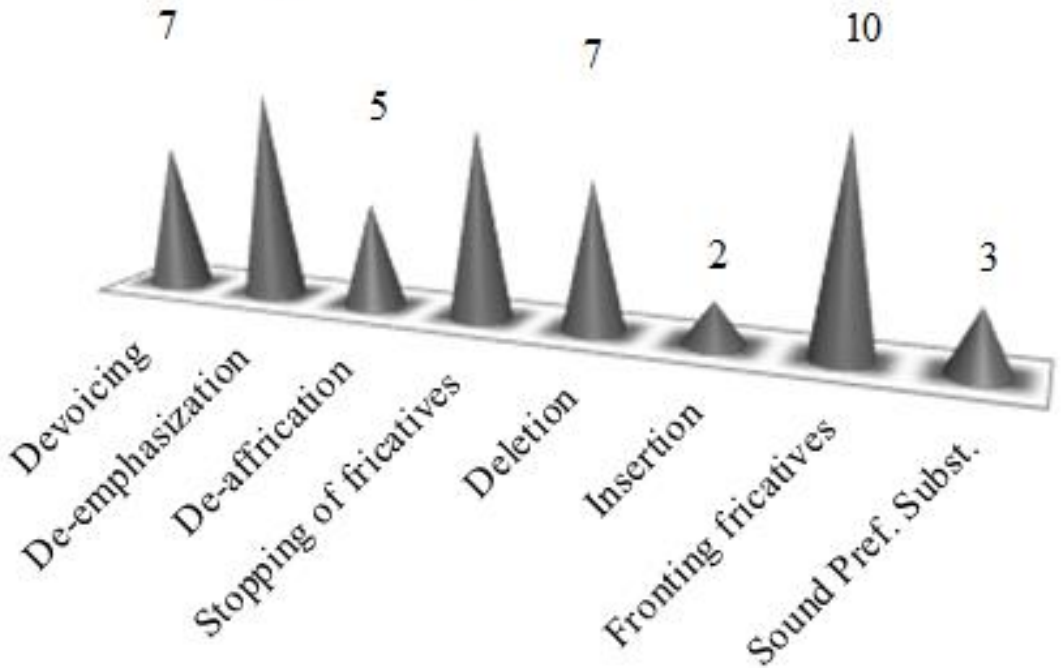

Figure 6. Types of Phonological Processes amongst children of TD

\subsection{Phonological Disorders for the ADHD Group}

The data has shown some similarities in terms of the types of phonological disorders between both groups, as in the examples found in (19-23 in Table 1) for the words; Corn, Triangle, Ear, Nest, and Rabbit. However, it was frequently and significantly noticed that more than one phonological process would occur in an attempt to pronounce a word by the ADHD group. The total number of types of phonological processes amongst the ADHD group was 20, which is almost double the amount of errors in the TD group. In the following table, we can see three processes occurring at once in example (1), with the word /naðða:ra/ which was pronounced as /Rada:la/, by one child and as /Ratta:ja/ by another. In both occurrences, there was initial glottal replacement of the nasal sound, stopping of a fricative, and trill / $\mathrm{r} /$ replacement with a lateral /// or glide /j/.

Other occurrences with two or more processes can be seen in Table 2 in examples $(2-5),(9-11)$ and $(13,15,17)$. As a comparison between both groups, the word 'flower' was pronounced differently by both groups. It was noticed that in the TD, that the Arabic word for 'flower', /zuhu:r/ was pronounced as /zuhu:1/ with a Lateral /// replacing the Till /r/. However, in the ADHD group, the same word 'flower' was pronounced as / $\partial u$ uh $/$ with two phonological errors instead of one: fronting of the fricative $/ \mathrm{z} /$ and final consonant deletion of the trill /r/. Also, in example (12) the word 'blue' /Razraq/ was pronounced as / $\mathrm{a}$ ðrak/, with two processes as well in the ADHD group. The same word was pronounced as/Paðraq/ in the TD group with only one error (see Table 1, example 8). Also, several syllables (vowel + consonant) were deleted, as in the example with word 'comb' in (14, Table 2), in which /mufut/ was pronounced as /mut/.

Table 2. Phonological Processes for ADHD group

\begin{tabular}{|c|c|c|c|}
\hline $\begin{array}{l}\text { Eg. } \\
\text { Number }\end{array}$ & Type of Phonological Disorder & Examples & Translation \\
\hline 1 & $\begin{array}{l}\text { 1. Stopping of fricatives; } \\
/ \check{\partial} / \rightarrow[\mathrm{d}, \mathrm{t}] \\
\text { 2. Initial Glottal Replacement; } / \mathrm{n} / \rightarrow \\
\text { [?] } \\
\text { 3.Trill replacement; } \\
/ \mathrm{r} / \rightarrow[1, \mathrm{j}, \mathrm{R}]\end{array}$ & $\begin{array}{l}\text { /nadða:ra/ pronounced as /Rada:la/ or } \\
\text { /Ptta:ja/ or /Pada:Pa/ }\end{array}$ & Eye Glasses \\
\hline 2 & $\begin{array}{l}\text { 1. Denazalization: Stop replaces nasal; } \\
/ \mathrm{m} / \rightarrow[\mathrm{b}] \\
\text { 2. Backing of fricatives: Alveolar } \\
\text { replaces labiodentals; } / \mathrm{f} / \rightarrow[\mathrm{s}]\end{array}$ & $\begin{array}{l}\text { /mufta: } \hbar / \text { pronounced as /busta: } \hbar / \text { or } \\
\text { /bufta: } \mathrm{h} /\end{array}$ & Key \\
\hline 3 & $\begin{array}{l}\text { 1. Denazalization; } / \mathrm{m} / \rightarrow[\mathrm{b}] \\
\text { 2. Replacement; } / \mathrm{b} / \rightarrow[\mathrm{r}]\end{array}$ & /samb/ pronounced as /s sabr/ & Glue \\
\hline 4 & $\begin{array}{l}\text { 1.Fronting of fricatives: dental fricative } \\
\text { replaces alveolar; } \\
\mid \mathrm{z} / \rightarrow[ð] \\
\text { 2.Final sound deletion; } \\
/ \mathrm{r} / \rightarrow[\varnothing]\end{array}$ & /zuhu:r/ pronounced as /ðuhu:/ & Flowers \\
\hline
\end{tabular}




\begin{tabular}{|c|c|c|c|}
\hline 5 & $\begin{array}{l}\text { 1.De-emphasization: emphatic stop } \\
\text { becomes non-emphatic; } \\
\text { /d } / \rightarrow[\mathrm{d}, \mathrm{t}] \\
\text { 2.Medial consonant deletion; } \\
\text { /d / } \rightarrow[\emptyset] \\
\text { 3. Glottal Replacement; } \\
/ \mathrm{S} / \rightarrow[?]\end{array}$ & /dufdaS/ pronounced as /dufa?/ or /tuftaS/ & Frog \\
\hline 6 & $\begin{array}{l}\text { Medial syllable deletion: } \\
\text { /ud/ } \rightarrow[\emptyset]\end{array}$ & /Puðun/ pronounced as /?un/ & Ear \\
\hline 7 & $\begin{array}{l}\text { De-emphasization: emphatic sound } \\
\text { becomes non-emphatic; } / \mathrm{t} / \rightarrow[\mathrm{t}]\end{array}$ & /batta/ pronounced as /bata/ & Duck \\
\hline 8 & $\begin{array}{l}\text { De-affrication: an affricate is reduced } \\
\text { to a stop; } \\
/ \mathrm{d}_{3} / \rightarrow[\mathrm{d}]\end{array}$ & /ridzil/ pronounced as /ridil/ & Leg \\
\hline 9 & $\begin{array}{l}\text { 1.Stop replaces fricative and bilabial } \\
\text { stop; } / \underline{\mathrm{s}} / \rightarrow[\underline{\mathrm{t}}, \mathrm{b}] \\
\text { 2. Final word deletion; } \\
/ \mathrm{S} / \rightarrow[\varnothing]\end{array}$ & /PusbaS/ pronounced as / Putta/ & Finger \\
\hline 10 & $\begin{array}{l}\text { 1.Initial Glottal replacement; } \\
/ \mathrm{k} / \rightarrow / \mathrm{r} / \\
\text { 2. Medial sound deletion; } / \mathrm{r} / \rightarrow[\varnothing] \\
\text { 3. Stopping of fricatives; } \\
/ \mathrm{s} / \rightarrow[\mathrm{t}]\end{array}$ & /kursi/ pronounced as /?uti/ & Chair \\
\hline 11 & $\begin{array}{l}\text { Distortion: Change in sound quality of } \\
\text { the sounds; } \\
/ s, \partial, z / \rightarrow\left[s_{\circ}, \partial_{\circ}, z_{\circ}\right]\end{array}$ & $\begin{array}{l}\text { /ваss。a:la/ } \\
\text { /z。ara:fa/ } \\
\text { /zuhu:r/ } \\
\text { /lad id。/ }\end{array}$ & $\begin{array}{l}\text { Washing- } \\
\text { Machine } \\
\text { Giraffe } \\
\text { Flowers } \\
\text { Delicious }\end{array}$ \\
\hline 12 & $\begin{array}{l}\text { 1.De-emphasization; } \\
\text { /q/ } \rightarrow[\mathrm{k}] \\
\text { 2.Fronting of fricatives: dental fricative } \\
\text { replaces alveolar; } \\
/ \mathrm{z} / \rightarrow[\mathrm{d}]\end{array}$ & /Pazraq/ pronounced as/Paðrak/ & Blue \\
\hline 13 & $\begin{array}{l}\text { 1.Stopping of fricatives: stop replaces } \\
\text { fricative; } / ð / \rightarrow[\mathrm{d}] \\
\text { 2.Final word deletion; } \\
/ \mathrm{n} / \rightarrow[\varnothing] \\
\text { 3. vowel replacement; } / \mathrm{u} / \rightarrow[\mathrm{i}]\end{array}$ & /Puðun/ pronounced as /Pidi/ & Ear \\
\hline 14 & $\begin{array}{l}\text { Deletion: Middle syllable deletion; /uf/ } \\
\rightarrow[\varnothing]\end{array}$ & /mufut/ pronounced as /mut/ & Comb \\
\hline 15 & $\begin{array}{l}\text { 1.De-affrication; } / \mathrm{d}_{3} / \mathrm{C} \rightarrow[\mathrm{d}] \\
\text { 2.Middle consonant deletion; } / \mathrm{r} / \rightarrow[\varnothing]\end{array}$ & /durdz/ pronounced as /dud/ & Drawer \\
\hline 16 & $\begin{array}{l}\text { Sound Preference Substitution: lateral } \\
\text { replaces trill; } / \mathrm{r} / \rightarrow[1]\end{array}$ & /ridzil/ pronounced as /lidzil/ & Leg \\
\hline 17 & $\begin{array}{l}\text { 1.Initial glottal replacement; } \\
/ \mathrm{x} / \rightarrow[?] \\
\text { 2. Sound Preference Substitution: } \\
\text { lateral replaces trill; } / \mathrm{r} / \rightarrow[1]\end{array}$ & /xarūf/ pronounced as / Palūf/ & Sheep \\
\hline 18 & $\begin{array}{l}\text { Final syllable Replacement: } \\
\text { /a?/ } \rightarrow[1]\end{array}$ & /dawa:?/ pronounced as /dawal/ & Medicine \\
\hline 19 & $\begin{array}{l}\text { Stopping of fricatives: stop replaces } \\
\text { fricative; } / / / \rightarrow[\mathrm{d}]\end{array}$ & /ðura/Pronounced as /dura/ & Corn \\
\hline 20 & $\begin{array}{l}\text { Baking of fricatives: alveolar fricative } \\
\text { replaces Dental fricative; } / \Theta / \rightarrow[\mathrm{s}]\end{array}$ & 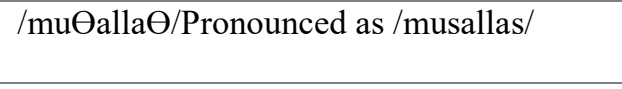 & Triangle \\
\hline 21 & $\begin{array}{l}\text { Stopping of fricatives: Stop replaces } \\
\text { fricative; } / ð / \rightarrow[\mathrm{d}]\end{array}$ & /Puðun/ Pronounced as /?udun/ & Ear \\
\hline 22 & $\begin{array}{l}\text { Insertion: adding a stop at word } \\
\text { endings; }[\emptyset] \rightarrow / \mathrm{b} /\end{array}$ & $/ \mathrm{Gu} / /$ pronounced as $/ \mathrm{Gu} \mathrm{Jb} /$ & Nest \\
\hline 23 & $\begin{array}{l}\text { Assimilation: nasal sound } / \mathrm{n} / \text { is } \\
\text { repeated and replaces nearest sound } \\
\text { which is } / \mathrm{r} / \text {; } \\
/ \mathrm{r} / \rightarrow[\mathrm{n}]\end{array}$ & /Parnab/ pronounced as / Pannab/ & Rabbit \\
\hline 24 & $\begin{array}{l}\text { 1.Metathesis: syllable switch; /ði/ } \rightarrow[\mathrm{f}] \\
\text { 2. lateral replaces trill; } \\
/ \mathrm{r} / \rightarrow[\mathrm{l}]\end{array}$ & /difirir/ pronounced as /fiðil/ & Fingernail \\
\hline
\end{tabular}


Although many of the error patterns observed in the pronunciation of children with ADHD were also noticed amongst normal children, other error patterns were indeed specific to children with the disorder. Therefore, the stages of Arabic consonant acquisition for ADHD development are different from those of TD group. It was discovered that the ADHD group demonstrated a significant number of Arabic phonological processes that were distinctive from the TD group. These phonological processes included frequent errors such Stopping/Backing of Fricative; Initial/Glottal Stop Replacement; Medial Consonant Deletion; Lateral Replacement; Distortion; Metathesis and Assimilation, as displayed in Figure 7 bellow.

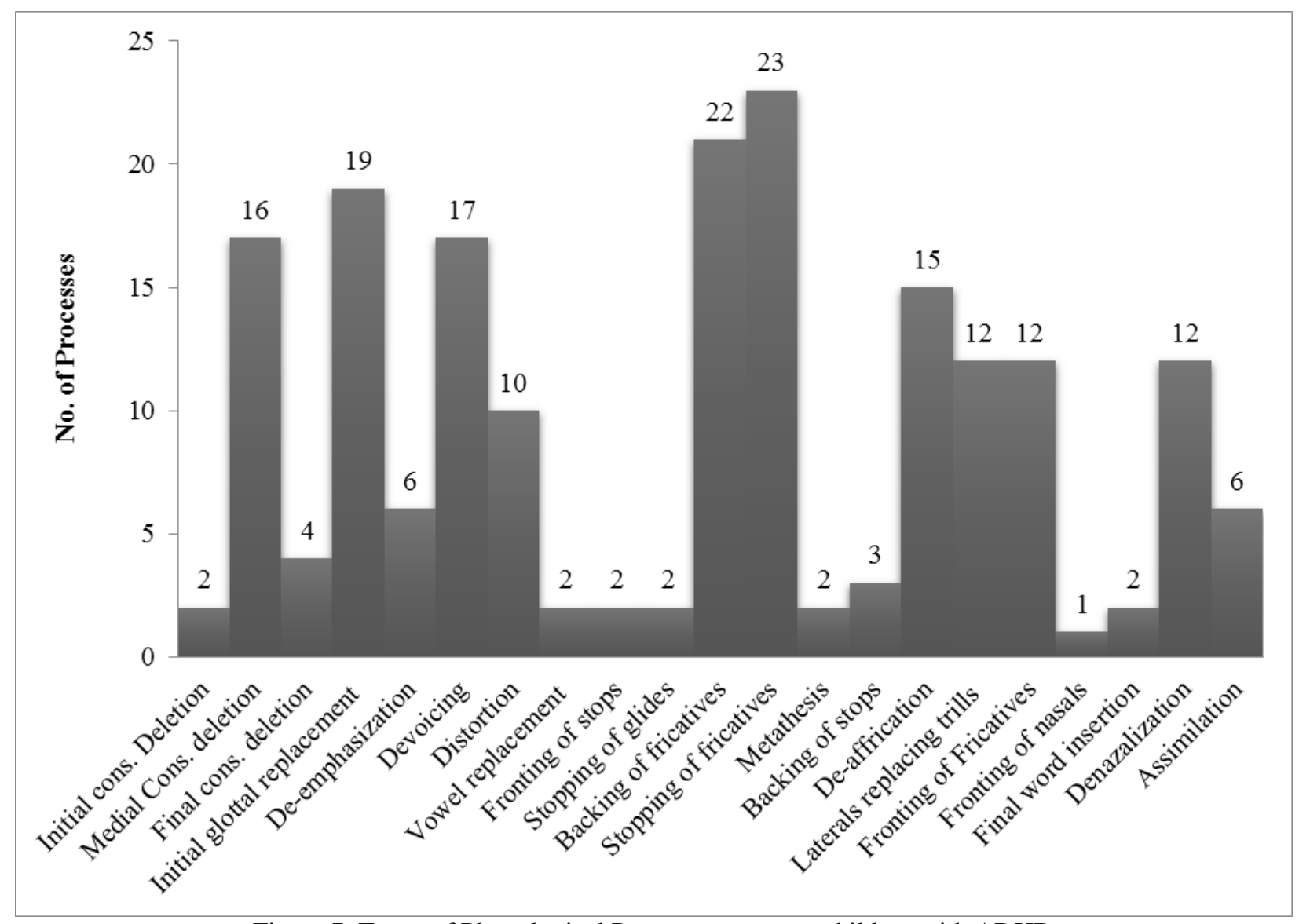

Figure 7. Types of Phonological Processes amongst children with ADHD

\section{Discussion}

The importance of identifying the normal progression of phoneme learning and distinguishing it from disordered or delayed phonological development was emphasized by Amayreh (2003). The data has been found to support this statement, as the implications of Amayreh's (2003) study results were used as an important reference point in this current study, which is the diagnosis of articulatory and phonological disorders amongst children with language disorders. Amayreh (2003) stated that in order for a child with intelligibility problems (such as one with ADHD) to have appropriate treatment for Speed Sound Disorder at a clinic or speech institute, they will need to be compared with children who speak similar dialects. Therefore, children of a similar background and age have been included in this study in order to provide an adequate comparison in terms of Arabic speech sound acquisition amongst two groups of children (TD and ADHD).

Furthermore, Amayreh (2003) suggested that once a child's errors are identified and remediated after being assessed, further analysis and attention to the production of the Educated Spoken Arabic (ESA) forms may be needed to develop phonological awareness for reading. Within the findings of this study, it was recognized that children with ADHD have articulation difficulties with most of the Arabic consonants, and produce almost three times the number of phonological errors as compared to children of Typical Development.

One of the research questions this study was based on is how the articulation and phonological errors amongst the ADHD group and TD group are both similar and different. Regardless of the similarities in terms of types of phonological processes between both groups (particularly with the Arabic fricatives), it was discovered that more than one phonological process would occur in an attempt to pronounce a single word within the ADHD group. In fact, that same group produced almost twice as many phonological errors as the TD group (21 for ADHD, and 11 for TD). Therefore, the stages of Arabic consonant acquisition for ADHD Development are different from those of Typical Development. 
Amayreh (2003) suggested that children between the ages (6-8) years who do not produce the /G/, /t/, or /z/ (sounds with no dialectal variants) would need to be assisted in mastering these consonants for the sake of communication. For that reason, and based on the results of this study, children with ADHD are precisely the kind of children this advice is applicable to, since they not only have problems producing ESA, but also in producing dialectal variants as well. Thus, speech-language intervention is necessary for the purpose of helping children with ADHD acquire their local Arabic dialectal form. Again, speech-language intervention is required for the purpose of making the transition to the standard form, in order to be able read and spell Arabic words correctly.

This research also sought out to find out if children with ADHD acquire their Arabic consonants and phonology in the same way and following the same developmental stages as children with TD. It was discovered that the ADHD group had indeed failed to acquire most of their Arabic consonants as they should have, and according to the developmental stages distinguished in Amayreh's study (2003). Also, through the comparison with the TD group, dramatic differences emerged regarding the number of Arabic consonants that had not been acquired by the age of 6 .

According to Amayreh's (2003) study results, the consonants /d/, /q/, /z/, / / / should have been acquired by the ages of 6;6- 7;4, but they had not been acquired amongst the ADHD group. Even some sounds that are from the earlier stage (23) were not being produced correctly by the same group, such as the sounds $/ \mathrm{k} /, / \mathrm{h} /, / \mathrm{f} /, / \mathrm{b} /, / \mathrm{m} / \mathrm{and} / \mathrm{d} /$. The sounds which belonged to the intermediate group (such as $/ \mathrm{x} /, / \mathrm{r} /$, and $/ \mathrm{f} /$ ) had still not been acquired by all the children. The sounds, which this group had used to replace other sounds, were the following: / $/ / / \mathrm{t} / \mathrm{/} / \mathrm{s} /$, and $/ \mathrm{d} /$. For example, the alveolar stop [d] replaced $/ \delta /$ and $/ \mathrm{d} z /$, and the $[\mathrm{t}$ ] replaced $/ \mathrm{s} /, / \mathrm{d} /, / \mathrm{J} /$, and $/ \Theta /$. The easiest fricative $[\mathrm{s}]$ replaced the sounds $/ \mathrm{f} /, / \mathrm{d} z /, / \Theta /$ and $/ \mathrm{z} /$. Finally, the glottal stop [?], which the children had the least problem with, was used to replace most sounds such as $/ \mathrm{d} z /, / \mathrm{/} /, / \mathrm{m} /, / \mathrm{q} /, / \mathrm{s} /, / \Theta /, / \mathrm{m} /, / \mathrm{n} /, / \mathrm{z} /$ and $/ \mathrm{d} /$. Although many of the error patterns observed in the children with ADHD were also produced by the other normal children, some error patterns were indeed specific to children with ADHD. Therefore, the developmental stages of Arabic consonant acquisition for children with ADHD are different from those of Typical Development. Figure 8 bellow demonstrates the most common sound substitutions amongst the ADHD group:

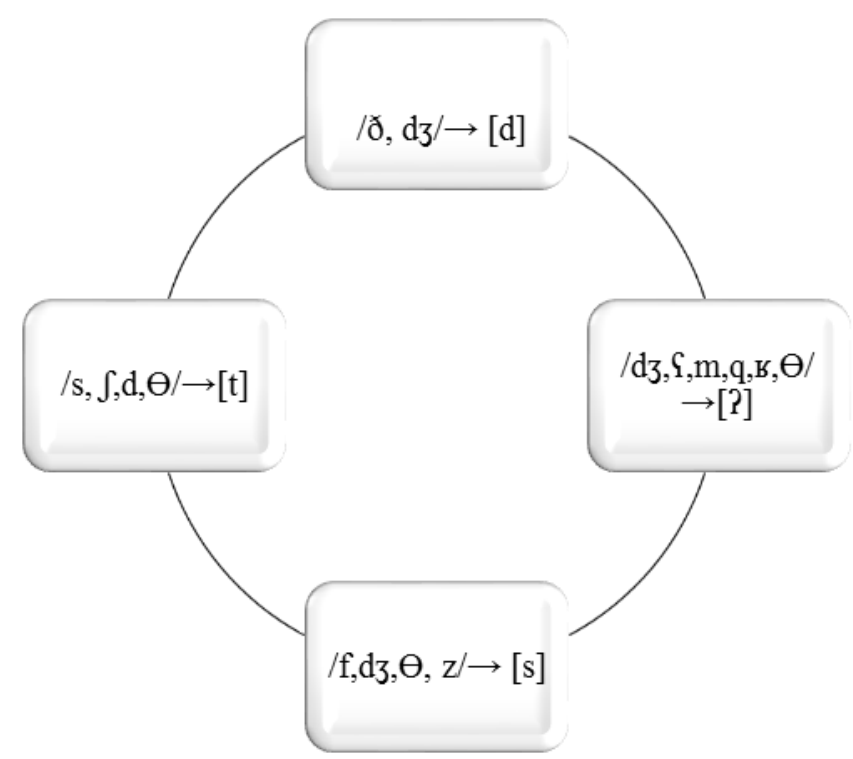

Figure 8. Common sound substitutions amongst children with ADHD

The TD group had acquired most of their Arabic consonants quite well, correctly pronouncing 16 consonants $100 \%$ accurately with minor changes occurring amongst 12 sounds only. The rest of the 16 consonants were in the middle range, as they were considered quite difficult $(73 \%-30 \%)$ in the following order: /t/, /b/, /d /, /n/, /k/, /x/, /ff/, /r/, /h/, /f/, / $\mathrm{h} /, / \mathrm{S} /, / \mathrm{s} /, / \mathrm{z} /, / \mathrm{s} /$, and $/ \mathrm{d} /$. Some of the common phonological errors found in Amayreh's study included the following: De-emphasization of emphatic sounds: $/ \mathrm{t}, \mathrm{d} / \rightarrow[\mathrm{t}, \mathrm{d}], / \mathrm{q} / \rightarrow[\mathrm{k}, \mathrm{g}, \mathrm{?}], / \underline{\mathrm{d}} / \rightarrow[\mathrm{\delta}, \mathrm{d}], / \mathrm{s} / \rightarrow[\mathrm{s}]$, De-affrication: $/ \mathrm{d} z / \rightarrow[3]$, and Devoicing: / / / $\rightarrow[\hbar]$, which were also part of the phonological processes within the TD group included in this study. However, additional phonological errors emerged amongst the participants including: Fronting/Stopping of fricatives, Deletion and Insertion, although they were not very common. These additional processes were amongst the most common types of Arabic phonological processes identified in the checklist of Arabic phonological processes/disorders by the Saudi Institute.

One the other hand, more Arabic phonological processes were identified amongst the ADHD group which included: Stopping/Baking/Fronting of fricatives; Glottal stop replacement (initial position); Medial/Final consonant deletion; Assimilation; Lateral replacement; Denazalization; Distortion; Insertion and Metathesis. Other sound errors included: Backing/Fronting of stops; Vowel replacement, Initial consonant deletion. These additional processes were very common amongst the ADHD group and have been also identified in the JISH Checklist as common Arabic phonological processes/disorders. 
Based on the comparison between the ADHD and TD group, it was noticed that the children with ADHD had evident articulation and phonological disorders, as the number of errors produced by this group exceeded the acceptable number of Arabic consonant sound changes for their age. Also, through comparison with the TD group, dramatic differences emerged in the number of Arabic consonants that had not been acquired by the age of 6 . Furthermore, it was also discovered that the ADHD group demonstrated a significant number of Arabic phonological processes that were distinctive from the TD group. This study has therefore proven the comorbidity between two kinds of disorders: firstly, a psychiatric type, since Attention-Deficit/Hyperactivity Disorder is described as one of the most common psychiatric disorders in children. The second disorder is a linguistic type, since both articulation and phonological disorders have been investigated. Thus, the comorbidity between psychiatry/psychology and linguistics has once again been proven to be interrelated.

\subsection{ADHD Labels and SSD}

As mentioned in the literature review, ADHD includes three types of disorders: the predominantly inattentive type (ADD); the predominantly hyperactive/impulsive type (ADHD), and the combined type (ADHD/ADD). In the Redmond et al., (2011) study it was noted that they had not found any evidence that children with ADHD (combined type) had particular difficulties, and it remained an open question whether or not children with various ADHD designations are at greater risk for language difficulties. Furthermore, it was hypothesized in the McGrath et al. study (2008) that the inattentive symptoms of ADHD could be strongly associated with language difficulties more than the hyperactive/impulsive type. This hypothesis has been tested to answer the final research question and prove which of the three subtypes of ADHD is directly related to Arabic Speech Sound Disorders amongst participants who are receiving speech therapy.

The findings of this study have confirmed that all three types of ADHD can indeed affect a child's speech intelligibility. Of the 10 participants in this study with ADHD, five of them had the combined type ADHD/ADD, three had ADD, and two had ADHD. Only two participants had the Predominantly Hyperactive/Impulsive type (ADHD), and for that reason did not exhibit as much SSD as the other children with Predominantly Inattentive type (ADD) or Combined Type (ADHD/ADD). Those that had inattentive symptoms were a total of 8 children, and thus demonstrated more SSD than the other two. These results, by and large, agree with the McGrath et al. study (2008) regarding how the inattentive symptoms of ADHD could be strongly associated with language difficulties more than the hyperactive/impulsive type. Figure 8 bellow demonstrates the ratio of the ADHD participants used in this study:

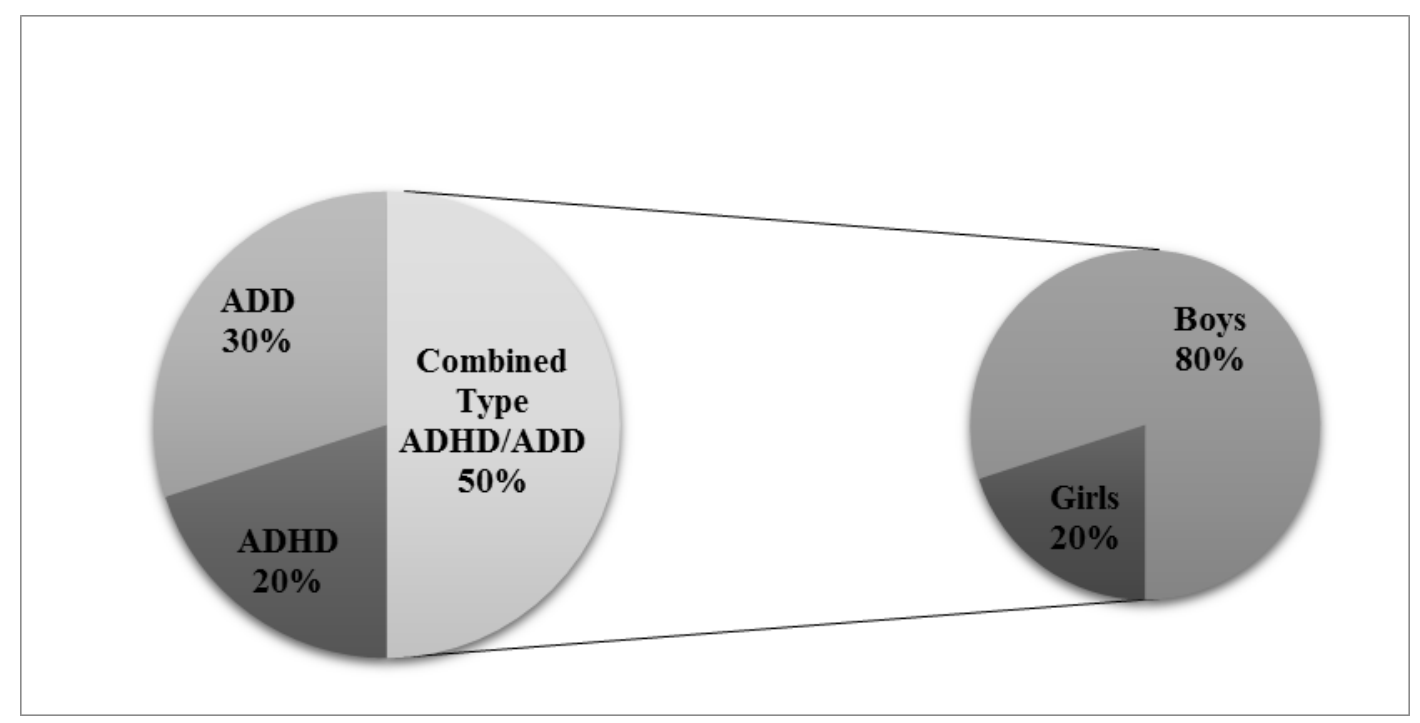

Figure 8. ADD/ADHD participant ration

\subsection{ADHD and Language Intervention}

Camarata \& Gibson (1999) were the first to introduce pragmatic deficits in relation to children with ADHD, and noted that intelligibility within the pragmatic domain cannot be distinguished from the phonological domain, because phonological disorders have a negative impact on the pragmatic domain as well. Given this high potential for pragmatic deficits in children with ADHD and the potential for disruptions in language learning processes, clinical evaluation of pragmatic skills would appear necessary, as asserted by Camarata \& Gibson (1999). This assumption is the initial argument from which this study seeks to emphasize regarding the negative effect that ADHD could have on a child's language if early intervention is neglected.

One of the hyperactive ADHD subjects in this study had been recently discharged from the institute at age of 6, after receiving two years of speech therapy. He was called back to be retested for this study using the articulation test, and produced several phonological errors which included: Devoicing, Stopping, Insertion, and Distortion. The DVD recorded session was observed by the researcher for the purpose of detecting progress. When the child had begun receiving speech therapy at the age of four, he had very limited expressive language including many phonological errors. Regardless of his hyperactive behavior, he had progressed quite well in terms of speech intelligibility. However, 
it was noticed by the researcher that he did not surpass his peers while being tested with other children of the same age during his final session at the institute.

Based on this study, significant phonological disorders have been detected amongst children with ADHD. Thus, one could argue that early intervention for these deficits should be a priority. Because of the comorbidity between ADHD and Speech Sound Disorder, speech-language pathologists (SLP) and audiologists must be aware of current perspectives on ADHD to facilitate effectively when working with patients with ADHD. According to the ASHA report (1997), SLP are often among the first to evaluate children and youth suspected of having ADHD due to the co-occurrence of ADHD with language learning disabilities and central auditory processing disorders.

\section{Recommendations for Further Studies}

This study may be limited in terms of size and number of participants. Although the findings have significantly shed light upon Arabic articulation and phonological disorders, other language areas also need to be investigated as well. This paper has been limited to subjects with ADHD syndromes; however, there are similar learning disorders that are also in need of investigation. Further research should investigate the effect of ADHD on other Arabic language areas, including syntax, semantics, pragmatics, and reading. The effect of ADHD on the academic performance of adolescents in schools should also be considered in future studies. In conclusion, it would be of immense value to have these findings verified in the future through applying them to data on a larger scale. Furthermore, this study highly recommends that schools permit research students to allow them access to student's records, in order to be able to identify and estimate more accurately the number of children in Saudi society with learning disorders due to ADHD, Autism Spectrum, and other mental disorders.

\section{Acknowledgments}

I am indebted to the people who supported me in this project. I would like to thank Professor Afnan Hussein Fatani, who made this project possible with her support and guidance. I am also grateful to the Jeddah Institute for Speech and Hearing (JISH) Director, Mrs. Sultana Alireza-Zahid (CED) for allowing me to conduct this study at the Institute.

\section{References}

Amayreh, M. M. (2003). Completion of the consonant inventory of Arabic. Journal of Speech, Language, and Hearing Research, 46, 517-529.

American Speech-Language-Hearing Association. (1997). Roles of audiologists and speech- language pathologists working with persons with attention deficit hyperactivity disorder. [Technical Report]. Retrieved from: www.asha.org/policy

Brown, T. E. (2005). Attention Deficit Disorder. USA: Yale University Press. 1-205

Camarata, S., \& Gibson, T. (1999). Pragmatic language deficits in attention-deficit hyperactivity disorder (ADHD). Mental Retardation and Developmental Disabilities Research Reviews, 5, 207 -214.

Cook et al. (1995). Association of attention-deficit disorder and the dopamine transporter gene. American Journal of Human Genetics, 56(4).

Cohen at al. (2000). The interference between ADHD and language impairment: An examination of language, achievement, and cognitive processing. Journal of Child Psychology and Psychiatry, 41(3), 353-362.

CHADD. (2011). Children and Adults with Attention-Deficit/Hyperactivity Disorder (CHADD). Retrieved from: http://www.chadd.org/

Currie, J., \& Stabile, M. (2006). Child mental health and human capital accumulation: The case of ADHD. Journal of Health Economics, 25, 1094-1118. Retrieved from: www.sciencedirect.com

Gillam et al. (2011). Communication sciences and disorders; from science to clinical practice. (2 ${ }^{\text {nd }}$ ed.). Massachusetts: Jones and Bartlett Publishers. 6-114.

Haidar, F. (2003) Co-morbidity and treatment of attention deficit hyperactivity disorder in Saudi Arabia. Eastern Mediterranean Health Journal, 9(5, 6), 988-995.

Holm et al., (1999). Identification and differential diagnosis of phonological disorder in bilingual children. Language Testing, 16(3), 271-293. Retrieved from: http://www.sagepublications.com/

Jeddah Institute for Speech and Hearing. Retrieved from: http://www.jish.org/Autism.html

Lee, D. (2004). Testing executive function models of adhd and its comorbid conditions: a latent variable approach. $P h$. D. dissertation. Retrieved from:http://txspace.di.tamu.edu/bitstream /handle/1969.1/2801/etd-tamu-2004B-SPSY Lee.pdf?sequence $=1$

Fewell, R., \& Deutscher, B., (2002). Attention Deficit Hyperactivity Disorder in Very Young Children: Early Signs and Interventions. Infants and Young Children, 14(3), 24-32.

Matthews, P. H. (2007). Oxford concise dictionary of linguistics. New York: Oxford University 
McIntosh, B., \& Dodd, B. (2008). Evaluation of Core Vocabulary intervention for treatment of inconsistent phonological disorder: Three treatment case studies. Child Language Teaching and Therapy, 25(1), 09-30. Retrieved from: http://www.sagepublications.com/

McGrath et al. (2008). Children with Comorbid Speech Sound Disorder and Specific Language Impairment are at Increased Risk for Attention-Deficit/Hyperactivity Disorder. Journal of Abnormal Child Psychology, 36, 151-163

Rief, S. (2005). How to Reach and Teach Children with ADD/ADHD. (2 $2^{\text {nd }}$ ed.). San Francisco: Jossey-Bass A Wiley Imprint. 3-64.

Redmond, S., Thompson, H., \& Goldstein, S. (2011). Psycholinguistic profiling differentiates specific language impairment from typical development and from attention- deficit/hyperactivity disorder. Journal of Speech, language, and hearing research, 54, 99-117.

Wolraich, M. (1999). Attention deficit hyperactivity disorder: The most studied and yet most controversial diagnosis. Mental Retardation and Developmental Disabilities Research Reviews, 5(3), 163-168. 